\title{
Generation and characterization of cross neutralizing human monoclonal antibody against 4 serotypes of dengue virus without enhancing activity
}

\author{
Subenya Injampa ${ }^{1,2}$ ， Nataya Muenngern ${ }^{1}$, Chonlatip Pipattanaboon \\ Khwanchit Boonha ${ }^{1}$ \\ Pitaksajjakul \\ Hathairad Hananantachai \\ Waranya Wongwit ${ }^{2}$ \\ ${ }^{1}$ Center of Excellence for Antibody Reserach, Faculty of Tropical Medicine, Mahidol University, Bangkok, Thailand \\ 2 Department of Social and Environmental Medicine, Faculty of Tropical Medicine, Mahidol University, Bangkok, Thailand \\ Corresponding Author: Pannamthip Pitaksajjakul \\ Email address: pannamthip.pit@mahidol.ac.th
}

Surachet Benjathummarak ${ }^{1}$,

Pongrama Ramasoota

Pannamthip

Background. Dengue disease is a leading cause of illness and death in the tropics and subtropics. Most severe cases occur among patients secondarily infected with a different dengue virus (DENV) serotype compared with those with the first infection, resulting in antibody-dependent enhancement activity (ADE). Our previous study generated the neutralizing human monoclonal antibody, D23-1B3B9 (B3B9), targeting the $1^{\text {st }}$ domain II of E protein, which showed strong neutralizing activity (NT) against all four DENV serotypes. However, at sub-neutralizing concentrations, it showed ADE activity in vitro. Methods. In this study, we constructed a new expression plasmid using the existing IgG heavy chain plasmid as a template for Fc modification at position N297Q by site-directed mutagenesis. The resulting plasmid was then co-transfected with a light chain plasmid to produce full recombinant IgG ( $r$ lgG) in mammalian cells (N297Q-B3B9). This rlgG was characterized for neutralizing and enhancing activity by using different FcyR bearing cells. To produce sufficient quantities of B3B9 rlgG for further characterization, $\mathrm{CHO}-\mathrm{K} 1$ cells stably secreting N297Q-B3B9 rlgG were then established. Results. The generated N297Q-B3B9 rlgG which targets the conserved $\mathrm{N}$-terminal fusion loop of DENV envelope protein showed the same cross-neutralizing activity to all four DENV serotypes as those of wild type rlgG. In both FcyRI- and RII-bearing THP-1 cells and FcyRII-bearing K562 cells, N297Q-B3B9 rlgG lacked ADE activity against all DENV serotypes at sub-neutralizing concentrations. Fortunately, the N297Q-B3B9 rlgG secreted from stable cells showed the same patterns of NT and ADE activities as those of the N297Q-B3B9 rlgG obtained from transient expression against DENV2. Thus, the CHO-K1 stably expressing N297Q-B3B9 HuMAb can be developed as high producer stable cells and used to produce sufficient amounts of antibody for further characterization as a promising dengue therapeutic candidate. Discussion. Human monoclonal antibody, targeted to fusion loop of envelope domainIl (EDII), was generated 
and showed cross-neutralizing activity to 4 serotypes of DENV, but did not cause any viral enhancement activity in vitro. This HuMAb could be further developed as therapeutic candidates. 
1 Generation and characterization of cross neutralizing human monoclonal antibody against

\section{4 serotypes of dengue virus without enhancing activity}

3 Subenya Injampa ${ }^{\mathrm{a}, \mathrm{b}}$, Nataya Muenngern ${ }^{\mathrm{b}}$, Chonlatip Pipattanaboon $^{\mathrm{b}}$, Surachet Benjathummarak ${ }^{\mathrm{b}}$,

4 Khwanchit Boonha $^{\mathrm{b}}$, Hathairad Hananantachai ${ }^{\mathrm{a}}$, Waranya Wongwit ${ }^{\mathrm{a}}$, Pongrama Ramasoota ${ }^{\mathrm{a}, \mathrm{b}}$,

5 Pannamthip Pitaksajjakul, b,

6

7 a Department of Social and Environmental Medicine, Faculty of Tropical Medicine, Mahidol

8 University, Thailand

$9 \quad{ }^{b}$ Center of Excellence for Antibody Research, Faculty of Tropical Medicine, Mahidol

10 University, Thailand

11

$12 *$ Corresponding author at: Department of Social and Environmental Medicine, Faculty of

13 Tropical Medicine, Mahidol University, Bangkok, Thailand, 420/6 Ratchathewi, Bangkok,

14 Thailand, 10400

15 E-mail address: pannamthip.pit@mahidol.ac.th (P. Pitaksajjakul). 


\section{Abstract}

Background. Dengue disease is a leading cause of illness and death in the tropics and

subtropics. Most severe cases occur among patients secondarily infected with a different dengue virus (DENV) serotype compared with those with the first infection, resulting in antibodydependent enhancement activity (ADE). Our previous study generated the neutralizing human monoclonal antibody, D23-1B3B9 (B3B9), targeting the $1^{\text {st }}$ domain II of E protein, which showed strong neutralizing activity (NT) against all four DENV serotypes. However, at subneutralizing concentrations, it showed ADE activity in vitro.

Methods. In this study, we constructed a new expression plasmid using the existing IgG heavy chain plasmid as a template for Fc modification at position N297Q by site-directed mutagenesis. The resulting plasmid was then co-transfected with a light chain plasmid to produce full recombinant IgG (rIgG) in mammalian cells (N297Q-B3B9). This rIgG was characterized for neutralizing and enhancing activity by using different FcyR bearing cells. To produce sufficient quantities of B3B9 rIgG for further characterization, CHO-K1 cells stably secreting N297QB3B9 rIgG were then established.

Results. The generated N297Q-B3B9 rIgG which targets the conserved N-terminal fusion loop of DENV envelope protein showed the same cross-neutralizing activity to all four DENV serotypes as those of wild type rIgG. In both Fc $\gamma$ RI- and RII-bearing THP-1 cells and Fc $\gamma$ RIIbearing K562 cells, N297Q-B3B9 rIgG lacked ADE activity against all DENV serotypes at subneutralizing concentrations. Fortunately, the N297Q-B3B9 rIgG secreted from stable cells showed the same patterns of NT and ADE activities as those of the N297Q-B3B9 rIgG obtained from transient expression against DENV2. Thus, the CHO-K1 stably expressing N297Q-B3B9 
40 HuMAb can be developed as high producer stable cells and used to produce sufficient amounts

41 of antibody for further characterization as a promising dengue therapeutic candidate.

42 Discussion. Human monoclonal antibody, targeted to fusion loop of envelope domainII (EDII),

43 was generated and showed cross-neutralizing activity to 4 serotypes of DENV, but did not cause

44 any viral enhancement activity in vitro. This HuMAb could be further developed as therapeutic

45 candidates. 
Introduction

Dengue infection is a leading cause of illness and death in the tropics and subtropics.

More than one-third of the world's population lives in areas at risk (Natasha Evelyn and Mikkel, 2013). DENV is a member of the Flavivirus genus in the Flaviviridae family. There are four antigenically different serotypes of DENV (DENV-1 to DENV-4) (Kuhn et al., 2002). Primary infection with one DENV serotype induces the production of homotypic neutralizing antibodies, which provide lifelong immunity against the infecting serotype. These homotypic neutralizing antibodies can cross-react but less specific against the other three DENV serotypes and persist for a period of several months to a few years (Guzman MG and Vazquez S, 2010). Upon secondary infection with heterologous DENV serotypes, these antibodies fail to neutralize virus resulting in an increase of infected cells and higher virus titers. This phenomenon is named antibody-dependent enhancement activity (ADE) (Halstead SB and O'Rourke EJ, 1977). Primary infection typically causes asymptomatic or self-limited dengue fever (DF). Whereas patients in secondary infection usually have an increased risk of developing severe disease, including lifethreatening dengue hemorrhagic fever/dengue shock syndrome (DHF/DSS)(Murphy BR and

82 Whitehead SS, 2011). though there are many studies of neutralizing antibodies against DENV, fully human monoclonal antibodies (HuMAbs) which are able to neutralize all four DENV serotypes without ADE 
86 activity are considered to be the main option for passive immune therapy (Marasco WA and Sui

87 J, 2007; Chan AC and Carter P, 2010; Low et al., 2017).

Previously, we generated HuMAb clone D23-1B3B9 (B3B9) with strong in vitro

89

90

91

92

93

94

95

96

97 neutralizing activity (NT) against DENV-1 to DENV-4 (Setthapramote et al., 2012). However, investigating the viral infection enhancing activity of this HuMAb on Fc-gamma receptor (FcyR)-bearing cells revealed an increase in DENV infection at sub-neutralizing concentrations, which limits its application as a therapeutic candidate (Sasaki et al., 2013). To diminish enhancing activity, modifications at glycosylation site Asn297, which influence the binding affinity between Fc region and FcyR presenting on immune effector cells, were established (Hristodorov et al., 2013; Chan AC and Carter PJ, 2010; Balsitis et al., 2010).

We constructed plasmids expressing antibody light chain (LC) and modified the Fc region of the heavy chain (HC) constant domain 2 at position N297Q by site-directed mutagenesis. The modified HC plasmid was co-transfected with the LC plasmid into HEK293T mammalian cells to produce full recombinant $\mathrm{IgG}(\mathrm{rIgG})$. To evaluate the Fc-modified rIgG as a potential therapeutic candidate for dengue treatment, NT and ADE activity were determined in vitro and compared with those of wildtype rIgG. We also demonstrate the mimic binding epitope on envelope protein of dengue virus for understanding specificity and functionality of this HuMAb.

\section{Materials and Methods}

\section{Cell lines and DENV strains}

HEK293T cells were maintained in Dulbecco's modified Eagle medium (Gibco, Grand Island, New York, USA.) with 10\% fetal bovine serum (FBS). For NT test, Vero cells were 
109 cultured in minimal essential medium (MEM) (GE Healthcare UK Ltd., Buckinghamshire, UK)

110 with $10 \%$ fetal bovine serum. THP-1 and K562 cells, which were used in ADE assays, were

111 cultured in RPMI 1640 medium (Gibco) with 10\% FBS. The DENV strains used in this study

112 were the Mochizuki strain of DENV1, the 16681 strain of DENV2, the H87 strain of DENV3,

113 and the H241 strain of DENV4. All DENVs were propagated in C6/36 cells, which were

114 maintained in Leibovitz's L-15 medium (Gibco) supplemented with 10\% FBS and 0.3\% of

115 BACTO Tryptose Phosphate Broth (TPB) (Sigma-Aldrich, Missouri, USA). CHO-K1 cells were

116 maintained in MEM medium supplemented with 10\% FBS and 1\% non-essential amino acid

117 (Gibco). All cell lines were kindly provided by Research Institute for Microbial Diseases, Osaka

118 University.

119

120

Generation of wild type and mutated human monoclonal antibody clone B3B9

121 Plasmid construction

122

Variable HC and LC sequences of B3B9 HuMAb were previously isolated from

123

hybridoma cells and used for construction of HC and LC expression plasmids producing B3B9

124 rIgG (Pitaksajjakul et al., 2014). This HC plasmid was used as a template for N297Q

125

mutagenesis by site-directed mutagenesis with the In-Fusion Cloning System (In-Fusion ${ }^{\circledR}$ HD

126

Cloning Plus; Clontech Laboratories Inc., Shiga, Japan). Primers were designed according to the

127

manufacturer's instructions to mutate the amino acid at position 297 from asparagine to

128

glutamine. This system combines the action of the In-Fusion HD enzyme with inverse

129

polymerase chain reaction (PCR), which generates linearized DNA from a plasmid template. The

130

PCR reaction was composed of the CloneAmp Hifi PCR premix, $300 \mathrm{nM}$ each of forward and

131 reverse primer, $5 \mathrm{ng}$ of plasmid, and distilled water to final volume of $25 \mu 1$. The amplification 
132 was performed with 35 cycles of $98{ }^{\circ} \mathrm{C}$ for 10 seconds, $55^{\circ} \mathrm{C}$ for 15 seconds, and $72{ }^{\circ} \mathrm{C}$ for 5

133 seconds. The inverse PCR products were gel-purified using a PureLink ${ }^{\circledR}$ Quick Gel Extraction

134 Kit (Invitrogen, California, USA.) following the manufacturer's protocol. The linearized

135 plasmids obtained from inverse PCR were then fused by the In-Fusion enzyme, by following the

136 manufacturer's instructions. The reaction was performed at $50{ }^{\circ} \mathrm{C}$ for 15 minutes. The in-fusion

137 reaction was chemically transformed into Stella chemical competent cells. Individual clones

138 were randomly selected for DNA sequencing.

DNA sequencing and plasmid preparation

141 The DNA sequencing of the mutated HC plasmids were confirmed by Sanger sequencing

142 (Macrogen Inc., Korea). Potential N-glycosylation site of wild type and mutated B3B9 HuMAb

143 was identified using NetNGlyc 1.0 software (Gupta et al., 2004). Plasmids that contained the

144 target mutation were amplified in E. coli and isolated using a Purelink ${ }^{\mathrm{TM}}$ plasmid Midiprep kit

145 (Invitrogen) from $100 \mathrm{ml}$ culture for further transfection in mammalian cells.

Transient expression of N297Q-B3B9 rIgG in HEK293T cells

produce whole rIgG with the N297Q mutation as previously described (Pitaksajjakul et al., 2014). The culture medium containing secreted N297Q-B3B9 rIgG was collected and used in immunofluorescence assays (IFAs) to determine the DENV-binding activity. The N297Q-B3B9 rIgG was purified using a protein A affinity column and measured the concentration of N297QB3B9 rIgG by BCA protein assay kit (Thermo Scientific, USA.). The purity of purified antibody was determined by sodium dodecyl sulfate polyacrylamide gel electrophoresis. 
156 IFA for DENV-binding activity

157 IFAs were used to determine the binding and specificity of N297Q-B3B9 rIgG for all

158 four DENV serotypes. IFA plates were prepared by infecting Vero cells with DENV at a

159 multiplicity of infection of 0.01 as well as mocked infected. The plates were incubated for 3 days

160 before being fixed and permeabilized with 3.7\% paraformaldehyde and $0.1 \%$ Triton X-100,

161 respectively. Culture fluid from transfected cells was added, and the plates were incubated at 37

$162{ }^{\circ} \mathrm{C}$ for $1 \mathrm{~h}$. AlexaFluor 488-conjugated anti-human IgG (1:1000 dilution) (Invitrogen) was added

163 as secondary antibody. The result was observed under fluorescence microscope (IX71,

164 Olympus). For this assay, non-infected cells were used as a negative control.

165

166 HuMAb isotyping

167 The IgG isotype of the N297Q-B3B9 rIgG was determined by PCR as previously 168 described (Omokoko et al., 2014) using complementary DNA isolated from HuMAb clone B3B9

169 hybridoma as a template. The gene-specific primers used to amplify $\operatorname{IgG1},-2,-3$, and -4 are

170 listed in Supplementary Table 1. IgG1 and IgG3 were amplified using the same forward and

171 reverse primers. The primers were used to amplify the hinge region between the Fab and Fc parts

172 that produce different sized PCR products. IgG1 and IgG3 showed specific band at 211 and 346

173 bp, respectively. With separate PCR reactions, IgG2 and IgG4 were amplified by the same

174 reverse and different forward primers. These IgG2 and IgG4 PCR reactions showed $207 \mathrm{bp}$ and $175210 \mathrm{bp}$, respectively. The PCR reaction was composed of $0.5 \mu \mathrm{g}$ of cDNA, $1 \mathrm{mM}$ Tris- $\mathrm{HCl}(\mathrm{pH}$

176 8.0), $5 \mathrm{mM} \mathrm{KCl}, 1.25 \mathrm{mM}$ deoxyribonucleotide triphosphate (dNTP), 1.25 units of ExTaq DNA

177 polymerase (TAKARA, Shiga, Japan), and $5 \mathrm{mM}$ of each primer, with distilled water to a final 
178 volume of $25 \mu 1$. The amplification of each primer pairs was performed in separate reaction with

17935 cycles of $94^{\circ} \mathrm{C}$ for 30 seconds, $65^{\circ} \mathrm{C}$ for 30 seconds, and $72{ }^{\circ} \mathrm{C}$ for 30 seconds. The PCR

180 products were separated by agarose gel electrophoresis and visualized by staining with SYBR

181 Safe DNA Gel stain (Invitrogen).

182

183 Foci reduction neutralization test (FRNT)

184

FRNT assay was performed as previously described (Pitaksajjakul et al., 2014). DENV at

MOI 0.01 were mixed with different concentrations of purified HuMAbs (B3B9 or N297Q-

B3B9 rIgG) and incubated at $37^{\circ} \mathrm{C}$ for 1 hour. Each mixture was added to Vero cells in 96-well

cell culture plates and incubated for 2 hours. The plates were then overlaid with $2 \%$

carboxymethyl cellulose (CMC) in MEM medium with 2\% FBS and incubated for 2 days for

DENV4 and for 3 days for DENV1, 2, and 3. After that, the cells were fixed with 3.7\%

paraformaldehyde/PBS and 0.1\% Triton X-100/PBS. Immunostaining was performed by an

incubation with anti-DENV human antibody, followed by Alexa-conjugated anti-human IgG

$(\mathrm{H}+\mathrm{L})(1: 1000$ dilution). Foci numbers were counted under a fluorescence microscope. The

percent reduction was calculated by comparing the foci number for each antibody concentration

with the number of foci obtained from a virus-PBS mixture (negative control).

Antibody dependent enhancement (ADE) assay on K562 cells

The ADE activity of the N297Q-B3B9 rIgG was also assessed on Fc $\gamma$ RIIa-bearing K562

cells (Konishi et al, 2010). Antibodies at serial four-fold dilutions and viruses were mixed in 
$201 \mathrm{HuMAb}$-virus mixture was co-cultured at $37^{\circ} \mathrm{C}$ under $5 \% \mathrm{CO}_{2}$ for 2 days. The cells were fixed

202 with an acetone/methanol fixing solution at $-20^{\circ} \mathrm{C}$. Immunostaining was performed by adding

203 anti-DENV human antibody and incubating at $4{ }^{\circ} \mathrm{C}$ overnight. Horseradish peroxidase-

204 conjugated anti-human $\operatorname{IgG}(\mathrm{H}+\mathrm{L})$ diluted in $0.05 \%$ Tween and 1\% FBS in PBS was then added,

205 and the samples were incubated at $37^{\circ} \mathrm{C}$ for 1 hour. The signal was developed with a DAB

206 substrate solution (KPL, Maryland, USA.). Infected cell counts obtained from the test were

207 adjusted with the mean infected cell counts obtained with the four negative controls set in the

208 same experiment. The cut-off value for differentiating enhancing from non-enhancing activities

209 was calculated from the average plus three times the SD of the percentages of infected cells

210 obtained with the four negative controls.

211

212 Antibody dependent enhancement (ADE) assay on THP-1 cells

213 DENV at a multiplicity of infection of 0.1 was incubated with serially diluted antibodies

214 in serum-free RPMI medium at $37^{\circ} \mathrm{C}$ for 1 hour. Then, $150 \mu 1$ of $5 \times 10^{5}$ cells $/ \mathrm{ml}$ THP- 1 cells,

215 which express both FcyRI and II on their surfaces, were added and the samples were incubated at

$21637{ }^{\circ} \mathrm{C}$ under $5 \% \mathrm{CO}_{2}$. After 2 hours, RPMI medium with 4\% FBS was added. The cell-HuMAb-

217 DENV solution was incubated for 3 days, after which RNA was extracted from the infected cells

218 using TRIzol ${ }^{\circledR}$ reagent (Invitrogen). The viral RNA was quantified by a one-step Realtime PCR

219 using dengue virus specific primer and glyceraldehyde 3-phosphate dehydrogenase (GADPH) as

220 an internal control (Sasaki et al., 2013). The result is presented as the fold enhancement of virus

221 copies compared with the virus-PBS mixture (control). 
224 Phage affinity selection (Biopanning)

225 Human monoclonal antibody clone B3B9 that show cross-neutralizing activity to 4

226 serotypes of DENV was used for mapping the epitope (Rowley et al., 2004). Panning was

227 performed by using Ph.D.-12 and Ph.D.-C7C Phage Display Peptide Library Kit (New England

228 Bio Labs Inc., UK) according to the manufacturer's instructions. As described in the

229 manufacturer lab manual, the dodeca-and loop-constrained hepta- peptide library consists of 1.2

$230 \times 10^{9}$ electroporated sequences.

231 Briefly, $50 \mu 1$ of protein A/G magnetic beads were blocked with BSA by incubating at

232 room temperature for 1 hour, and washed with 0.1\% Tris Buffered Saline with Tween (TBST).

233 In the meantime, Phages $\left(5 \times 10^{10}\right.$ plaque forming units $\left.(\mathrm{PFU})\right)$ were incubated at room

234 temperature for 30 minutes with purified B3B9 HuMAb to a final volume of $200 \mu \mathrm{TBST}$.

235 Phage - HuMAb mixture was transferred to the tube containing the blocked magnetic beads and

236 incubated for 20 minutes at room temperature. After incubation, nonbinding phages that were not

237 captured on magnetic beads were washed with TBST. The bound phages were eluted with $1 \mathrm{ml}$

238 glycine elution buffer (0.2 M Glycine-HCl, $1 \mathrm{mg} / \mathrm{ml} \mathrm{BSA,} \mathrm{pH} \mathrm{2.2)} \mathrm{and} \mathrm{neutralized} \mathrm{with} 150 \mu 1$

239 of $1 \mathrm{M}$ Tris- $\mathrm{HCl}(\mathrm{pH} 9.1)$. Then, the bound phages were directly added to $20 \mathrm{ml}$ early-log

240 Escherichia coli (E. coli) ER2738 culture and incubated at $37^{\circ} \mathrm{C}$ with vigorous shaking for 4.5

241 hours. After incubation, the culture was transferred to a $50 \mathrm{ml}$ centrifuge tube and spun at 5,000

$242 \mathrm{rpm}$ for 15 minutes at $4{ }^{\circ} \mathrm{C}$. The phage-containing supernatant was transferred to a new $50 \mathrm{ml}$

243 centrifuge tube. These amplified phages were precipitated with 20\% PEG 8000/2.5 M NaCl at 4

$244{ }^{\circ} \mathrm{C}$ overnight, and centrifuged at $12,000 \mathrm{~g}$ for 15 minutes. Phage pellets were then resuspended

245 with $200 \mu 1$ TBS and used in the next cycle. Three rounds of selection were performed.

246 Specificity of selected phage clones were confirmed by phage ELISA. Briefly, 96-well microtiter 
247 plates were coated in triplicate well of $100 \mu \mathrm{B} 3 \mathrm{~B} 9 \mathrm{HuMAb}$ at $4^{\circ} \mathrm{C}$ overnight. Then, the wells

248 were washed 2 times with $0.05 \%$ Phosphate Buffered Saline with Tween (PBST). After that, the

249 wells were blocked with blocking buffer (3\% BSA in TBST). Then, phage lysate of each

250 selected clones from panning step was added to 2 wells of coated antibody. At this step, wild

251 type M13 phages were added to another HuMAb-coated well as a no fusion peptide control.

252 Consequently, anti-M13 antibody-HRP conjugated; dilute 1:5000 in blocking buffer were added.

253 All incubations were performed in humidity chamber at $37^{\circ} \mathrm{C}$, for 1 hour. After washing, the

254 reaction was developed using 3,3',5,5'-Tetramethylbenzidine (TMB) substrate (Sigma-Aldrich),

255 and terminated by adding $100 \mu \mathrm{l}$ of $2.0 \mathrm{M} \mathrm{H} 2 \mathrm{SO} 4$. The absorbance was measured at $450 \mathrm{~nm}$

256 using ELISA reader (TECAN). Plasmids from positive clones of ELISA were isolated and

257 sequenced using -96 gIII sequencing primer 5'-TGA GCG GAT AAC AAT TTC AC-3'. This

258 primer was used to amplify the fusion peptide region. The inserted random 7 and 12 amino acids

259 were identified and analyzed. All inserted sequences were aligned to determine the consensus

260 sequence. The obtained consensus sequences were aligned with dengue viral genome to

261 determine the mimic epitope.

262

263

264

Phage affinity binding by inhibition ELISA

After sequence analysis, inhibition ELISA was used to confirm candidate phages from

each group of inserted peptide sequences that had specifically bound to B3B9 HuMAb.

Reciprocal dilution of each phage clones were firstly determined to use in inhibition assay. For inhibition ELISA, B3B9 HuMAb was serially 2-fold diluted started at $20 \mu \mathrm{g} / \mathrm{ml}$. Then, the diluted antibody was incubated with equal volume of phage at specified dilution at room temperature for 1 hour. After incubation, the mixtures were transferred to HuMAb pre-coated 
270 plate, and incubated for another 1 hour. Bound phages to the coated HuMAb were detected by

271 anti-M13-HRP, and signal was developed with TMB substrate. The absorbance values were

272 measured at $450 \mathrm{~nm}$ using an ELISA reader (TECAN). Absorbance values of each concentration

273 (A) of antibody in solution phase were divided by absorbance values in the absence of antibody

274 (A0), yielding normalized values (A/A0) (Skottrup et al., 2012). Non-relevant anti-influenza

275 antibody, which was tested as negative binding with our selected dengue-specific phage clones,

276 was used as a negative control.

277

278 Generation of stable, antibody-secreting CHO-K1 cells

279

280

281

282

283

284

285

286

287

288

289

290

291

292

The HC-expressing constructed plasmid (pQCXIP-CH) contained a puromycin-resistant gene and the LC-expressing constructed plasmid (pQCXIH-CL) contained a hygromycinresistant gene. After determining the optimal concentrations of the corresponding two antibiotics, stable antibody-secreting $\mathrm{CHO}-\mathrm{K} 1$ cells were selected using puromycin and hygromycin at 8 $\mu \mathrm{g} / \mathrm{ml}$ and $800 \mu \mathrm{g} / \mathrm{ml}$, respectively. For stable cell generation, briefly, CHO-K1 cells were seeded in a 6-well cell culture plate the day before transfection to obtain a cell density of 9095\% on the next day. The medium was replaced with Opti-MEM I reduced serum medium. Plasmid DNA was mixed with transfection reagent (Lipofectamine 2000) and added to the cells, which were then incubated for 5 hours. After that, the medium was replaced with culture medium (10\% FBS, 1\% NEAA MEM). The cells were incubated at $37{ }^{\circ} \mathrm{C}$ with $5 \% \mathrm{CO}_{2}$ for 24 hours. After that, the medium was replaced with culture medium containing the two antibiotics at the concentrations specified above. The medium was changed every 3-4 days until $60 \%$ of alive cells were observed. The transfected cells were used for cell cloning by limiting dilution on 96 well-cell culture plates and incubated for 10-14 days with selection media. The positive clones 
293 that were able to secrete the target anti-DENV rIgG were selected by IFA using the culture

294 supernatant of each well containing a single stable clone. The cells were scaled up for further

295 characterization. The level of IgG contained in the culture fluid of each positive clone was

296 roughly determined by an IgG quantitation enzyme-linked immunosorbent assay (Bethyl

297 Laboratories, Inc., Texas, USA.). The functionalities of the purified N297Q rIgG secreted from

298 the stable cells were confirmed by IFAs, NT and ADE assays.

299

300

Results

301

Aglycosylated HuMAb clone B3B9 expressed by transient expression system showed cross

302

neutralizing activity to all serotypes of DENV without ADE activity

303

304

Wild type and mutated human monoclonal antibody clone B3B9 were generated and showed

305 cross reactivity to all serotypes of DENV.

306

The substitution of amino acid at position 297 from Asparagine to glutamine was created

307

308

309

310

311

312

313

314

315

Human monoclonal antibody clone B3B9 is IgG1 isotype

Reverse transcription PCR was performed to determine the B3B9 rIgG isotype. Using

B3B9 hybridoma complementary DNA as template, the PCR product with approximately $211 \mathrm{bp}$ of IgG1 was observed (Supplement fig. 1). 
317 Wild type and mutated human monoclonal antibody clone B3B9 showed cross neutralizing 318 activity against all serotypes of DENV

319 To determine the neutralizing activity of rIgG, we assessed the NT of N297Q-B3B9 rIgG 320 and B3B9 rIgG in Vero cells. N297Q-B3B9 rIgG displayed almost the same level of NT as the

321 B3B9 rIgG against all DENV serotypes. The NT levels of various concentrations of these two 322 antibodies against all four DENV serotypes are shown in Fig. 2A-D. Among these four 323 serotypes, B3B9 and N297Q-B3B9 rIgG showed identical 50\% reduction of FFU (NT50) to 324 DENV-2, 3, and $4(0.125 \mu \mathrm{g} / \mathrm{ml}$ for DENV2 and $2 \mu \mathrm{g} / \mathrm{ml}$ for both DENV3 and DENV4). However, the NT50 concentration against DENV1 of N297Q-B3B9 rIgG was slightly higher 326 than B3B9 rIgG (Fig.2E).

327

Mutated human monoclonal antibody clone B3B9 eliminated ADE activity in K562 cells while wild type showed ADE activity against all types of DENV B3B9 rIgG was able to neutralize DENV2 and 3 at the minimum concentration, 0.39 and $25 \mu \mathrm{g} / \mathrm{ml}$ respectively (Fig. 3B-C), but not neutralize to DENV1 (Fig. 3A) and 4 (Fig. 3D). Moreover, this antibody induced a virus infection enhancement at concentrations 400-0.0015 $\mu \mathrm{g} / \mathrm{ml}, 0.39-0.006 \mu \mathrm{g} / \mathrm{ml}, 100-0.0015 \mu \mathrm{g} / \mathrm{ml}$, and 400-0.00038 $\mu \mathrm{g} / \mathrm{ml}$ for DENV1, 2, 3, and 4, respectively (Fig. 3A-D). In contrary, N297Q-B3B9 rIgG showed NT for all four DENV serotypes and showed no enhancing activity in any of the tested antibody concentrations.

Mutated human monoclonal antibody clone B3B9 showed no ADE activity in THP-1 cells while wild type showed ADE activity against all types of DENV 
In THP-1 cells, mutant IgG (N297Q-B3B9) that cannot bind to Fc $\gamma$ R showed a complete

340

341

342

343

344

345

346

347

348

349

350

351

352

353

354

355

356

357

358

359

360

361

reduction of ADE activity in all tested antibody concentrations. In contrast, wild type rIgG induced 9541, 43, 3061, and 2020 fold enhancement in the dengue virus RNA copy number compared with the control for DENV1, 2, 3, and 4, respectively (Fig. 3E-H).

Epitope of B3B9 rIgG was within the highly conserved N-terminal fusion loop peptide of the E protein domain II

the affinity selection of purified B3B9 HuMAb. After biopanning, the number of output phages obtained from Ph.D. C7C and Ph.D.12 increased from $6.9 \times 10^{5}$ to $9.8 \times 10^{8}$ PFU and $6.9 \times 10^{5}$ to $7.7 \times 10^{8}$ PFU respectively, which proposed that specific enrichment had occurred (Fig 4A). Plasmids of phage clones that show binding activity with HuMAb by ELISA were isolated for DNA sequencing. Inserted oligonucleotide sequences of phage DNAs were translated to peptide sequences. Peptide sequences were aligned using BioEdit program 7.2.3 to analyze the epitopes and the binding motif of HuMAb. Phage clones were shown to display a consensus sequence LXXXG (Fig 4B). After comparing this peptide with the amino acid sequences of E proteins of DENV1-4, it was found that this LXXXG motif matched to 107LFGKG111 within the highly conserved N-terminal fusion loop peptide of the E protein domain II (Fig 4C). To investigate the solution-phase binding of each candidate phage random peptide with target B3B9 HuMAb, eight candidates phage clones which matched to the motif of 107LXXXG111 were selected for this study (Fig 4B, Table 1). From phage inhibition ELISA, it was found that the binding of all phage clones were inhibited by B3B9 HuMAb with dose-dependent manner, as shown in Fig 4D. 
N297Q-B3B9 rIgG producing from CHO-K1 stable cell lines showed neutralizing activity against DENV2 without enhancing activity

From 125 stable clones that were screened, one showed the highest IgG secretion level

$(9,587 \mu \mathrm{g} / \mathrm{ml})$. This clone was continually cultured to collect supernatant for purification.

Preliminary study against DENV2 showed that all tested concentrations of the modified rIgG secreted from the stable cell line showed the result of viral NT (Fig. 5A) and no ADE activity (Fig. 5B), the result as modified $\mathrm{rgG}$ secreted from transient expression.

\section{Discussion}

Due to the complexity of DENV infection and pathogenesis (Marasco and Sui, 2007), the ideal therapeutic antibodies should be fully human-derived and capable of inhibiting all four serotypes to reduce the risk of ADE causing more severe symptoms (Chan et al., 2013). We previously generated a cross-neutralizing HuMAb B3B9 (Setthapramote et al., 2012).

Although this HuMAb showed strong NT to all DENV serotypes, at sub-neutralizing concentrations, it promoted ADE activity (Sasaki et al., 2013). To overcome this problem, we generated $\mathrm{rIgG}$ with an engineered Fc to prohibit the binding between Fc portion and Fc receptor.

The important receptor for ADE mechanism is FcyR (Fc gamma receptor) that once it bind with immune complex can stimulates virus infection. Fc region of antibody contains asparagine residue (N297) which is a single N-linked glycosylation site in its $\mathrm{CH} 2$ domain. The nature of this glycan can decisively influence the therapeutic performance of a recombinant 
385 386

387

antibody, and their absence or modification can leads to changing of conformation and losing Fc effector functions (Hristodorov et al., 2013; Subedi and Barb, 2015). Fc fragment of antibody acquires the sugar moieties attached at position N297 residues to maintain the structure of antibody. Thus, deletion of the N-glycan changes the structure of the Fc portion resulting in diminished binding to Fcy receptor (Nimmerjahn and Ravetch, 2008).

Firstly, we evaluated the generated N297Q-B3B9 rIgG for its neutralizing activity in Vero cells and found that the engineering antibody showed proper neutralizing activity comparable to B3B9 rIgG against DENV2, -3, and -4 with some lesser degree of NT activity against DENV1 of N297Q-B3B9 comparing with B3B9 rIgG.

Since most of anti-dengue virus antibody could showed enhancing activity at subneutralizing concentration (Sasaki et al., 2013; Schmidt, 2010). The study in the cell absent of Fc $\gamma \mathrm{R}$ may not represent the neutralizing status in vivo. We then studied the balancing of NT and ADE activity using K562 cells, which express Fc $\gamma$ RII. In the simplified ADE assay using K562 cells (Konishi et al., 2010), the virus infection enhancement is represented as the number of infected cells from each antibody concentration compared with those from a control performed in the absence of antibody. In this cell type, we found that B3B9 $\mathrm{rgG}$, which showed crossneutralizing activity to 4 DENV serotypes in Vero cell, only neutralized DENV 2 and 3, but not DENV1 and 4 (Fig. 3A-D). In contrary, N297Q-B3B9 rIgG showed cross-neutralizing activity to 4 serotypes of DENV.

However, since K562 cell only expresses FcyRIIa, we further determined the ADE activity in THP-1 cells that expressed both FcyRI and FcyRII. In accordance with ADE study in K562 cells, our N297Q-B3B9 rIgG showed clearly reduction of viral enhancement activity in 
407 THP-1 cell. This result showed the potential of N297Q-B3B9 rIgG as a human monoclonal 408 therapeutic antibody that cross neutralizes all serotypes of DENV without enhancing activity. Many studies of Fc modification were explored for establishment of therapeutic antibodies candidates against dengue virus. In 1989, Tao and Morrison studied roles of aglycosylated chimeric mouse-human IgG antibody by modifying at glycan positions N297Q, N297H and N297K via site directed mutagenesis (Tao and Morrison, 1989). These aglycosylated antibodies cannot bind to human FcyRI and not trigger C1q binding ability of complement system (Tao and Morrison, 1989). Balsitis et al. (2010) reported that a N297Q mutation of mouse and chimeric human-mouse IgG that efficiency reduced ADE in vitro could decreased the mortality of DENV-infected mice (Balsitis et al., 2010). modified human monoclonal antibody at N297A and showed NT activity to be the same as its parental HuMAb. Nonetheless, this HuMAb still induced low levels of virus infection enhancement (Ramadhany et al., 2015). One possible reason might be the type of mutated amino acid used. Considering the amino acid structure, the substitution of Asparagine with Glutamine

422 (conservative mutation) reduces the effects of functional properties because the side chains of these two amino acids differ by only one methylene group. Thus the substitution amino acid is one of the essential factors that affect to the efficiency of antibody. display for finding specific epitope to several antiviral (Xue et al., 2012; Zhao et al., 2012), and anti-flavivirus monoclonal antibody (MAb) (Sun et al., 2011). This technique provides an economical and rapid approach for mapping antibody epitopes (Zhang et al., 2006; Chin et al., 429 2017). We mapped the epitopes of our HuMAb to LXXXG which correspond to 107LFGKG111 
430 located in the conserved N-terminal fusion loop of envelope domain II (EDII). In accordance

431 with our previous studies, this cross-neutralizing HuMAb B3B9 also targeted to DII of envelope

432 proteins residue 52-132, analyzed by western blot using truncated E protein (Sasaki et al., 2013).

433 This is a major target epitope of human antibodies for NT and ADE activity (Costin et al., 2013;

434 Deng et al., 2011). Comparing between epitopes which targeted murine and human MAb specific 435 to dengue virus (Shrestha et al., 2010; Sukupolvi Petty S et al., 2010, Schieffelin et al., 2010;

436 Beltramello et al., 2010; de Alwis et al., 2012), it was found that MAbs generated from mice are

437 mostly serotype-specific that targeting DIII of envelope protein (Shrestha et al., 2010).

438 However, most of the HuMAbs were targeted to DI-II of envelope proteins which is more cross-

439 reactive (Beltramello et al., 2010; de Alwis et al., 2012).

440 As a promising therapeutic candidate, it was described by Williams et al., (2013) that the

441 chimeric N297Q MAbs targeting fusion loop and dimer interface on EDII, but not the A strand

442 and C-C' loop on EDIII, acted therapeutically by competing against enhancing antibodies in

443 polyvalent serum that recognize the same or proximal epitopes. This kind of fusion loop specific

444 N297Q MAb showed protective activity in vivo when administered with enhancing titer of

445 polyserum (Williams et al., 2013). Thus, the identification of B cell epitope in this study is

446 crucial to understand its function and antibody/epitope interaction.

447 For antibody production, in this study, we used HEK293T cell for transient expression

448 mainly because of its higher transfection efficiency and expression level, resulting in lower

449 development costs when compare to stable cell line development (Zhang et al., 2012). However,

450 for further characterization of N297Q-B3B9 rIgG as a dengue therapeutic candidate large

451 quantities of antibody, with high stability in both production yield and quality, were required.

452 Therefore, stable expression was used as an alternative solution for antibody production. CHO- 
$453 \mathrm{~K} 1$ cells were used for stable cell line generation. This cell line is the prominent system for bio-

454 manufacturing of therapeutic products (Hossler et al., 2009) as 70\% of the therapeutic protein

455 was produced by this system (Croset et al., 2012). Characterization of this antibody in the other

456 aspects such as stability, pharmacokinetics or phamacodynamics of antibody (Liming, 2015) was

457 required because protein produced by HEK293T cells and CHO-K1 cells show different patterns

458 of glycosylation. However, we found no differentiation of NT and ADE activity in both cell

459 types (Figure 5).

460 Together, our results suggest that N297Q-B3B9 rIgG is a human monoclonal antibody

461 that can neutralize all four serotypes of DENV without viral enhancing activity. As a fully

462 human-derived monoclonal antibody, it avoids the problem of a human anti-mouse antibody

463 response.

464 Since interaction of Fc-FcyR on innate immune cells trigger immune effector functions

465 such as antibody dependent cell-mediated cytotoxicity (ADCC), complement-dependent

466 cytotoxicity (CDC) (Kellner et al., 2014), and antibody dependent cellular phagocytosis (ADCP)

467 (Algirdas et al., 2015). After thoroughly characterization of these functions, this B3B9 rIgG can

468 be a model testing for dengue therapeutic treatment.

469

470 Acknowledgements

471 The authors would like to thank Dr. Atsushi Yamanaka for his continuous advisement

472 and encouragement.

473

474 References 
475 Balsitis SJ, Williams KL, Lachica R, Flores D, Kyle JL, Mehlhop E, Johnson S, Diamond MS,

476 Beatty PR, Harris E. 2010. Lethal antibody enhancement of dengue disease in mice is prevented

477 by Fc modification. PLoS. Pathogen 6: e1000790.

478 Beltramello M, Williams KL, Simmons CP, Macagno A, Simonelli L, Quyen NT, Sukupolvi-

479 Petty S, Navarro-Sanchez E, Young PR, de Silva AM, Rey FA, Varani L, Whitehead SS,

480 Diamond MS, Harris E, Lanzavecchia A, Sallusto F. 2010. The human immune response to

481 Dengue virus is dominated by highly cross-reactive antibodies endowed with neutralizing and

482 enhancing activity. Cell Host Microbe 8: 271-283.

483 Chan AC and Carter PJ. 2010. Therapeutic antibodies for autoimmunity and inflammation. Nat

484 Rev Immunol 10(5): 301-16.

485 Chan KR, Ong EZ, Ooi EE. 2013. Therapeutic antibodies as a treatment option for dengue fever.

486 Expert Review of Anti-Infective Therapy 11: 1147-1157.

487 Chin CF, Lai JY, Choong YS, Anthony AA, Ismali A, Lim TS. 2017. Delineation of B-cell

488 epitopes of Salmonella enterica serovar Typhi Haelysin E: Potential antibody therapeutic target.

489 Scientific Report 7:2176 DOI:10.1038/s41598-017-01987-8.

490 Croset A, Delafosse L, Gaudry JP, Arod C, Glez L, Losberger C, Begue D, Krstanovic A, Robert

491 F, Vilbois F, Chevalet L, Antonsson B. 2012. Differences in the glycosylation of recombinant

492 proteins expressed in HEK and CHO cells. J Biotechnol; 161: 336- 48.

493 Costin JM, Zaitseva E, Kahle KM, Nicholson CO, Rowe DK, Graham AS, Bazzone LE,

494 Hogancamp G, Figueroa Sierra M, Fong RH, Yang ST, Lin L, Robinson JE, Doranz BJ,

495 Chernomordik LV, Michael SF, Schieffelin JS, Isern S. 2013. Mechanistic study of broadly

496 neutralizing human monoclonal antibodies. $J$ Virol; 87(1): 52-66. 
497 Costin JM, Zaitseva E, Kahle KM, Nicholson CO, Rowe DK, Graham AS, Bazzone LE,

498 Hogancamp G, Figueroa Sierra M, Fong RH, Yang ST, Lin L, Robinson JE, Doranz BJ,

499 Chernomordik LV, Michael SF, Schieffelin JS, Isern S. 2012. Identification of human

500 neutralizing antibodies that bind to complex epitopes on dengue virions. Proc Natl. Acad Sci

501 U.S.A 109: 7439-7444.

502 Deng YQ, Dai JX, Ji GH, Jiang T, Wang HJ, Yang HO. 2011. A broadly flavivirus cross-

503 neutralizing monoclonal antibody that recognizes a novel epitope within the fusion loop of $\mathrm{E}$

504 protein. PLoS One; 6(1): e16059.

505 Grevys A, Bern M, Foss S, Bratlie DB, Moen A, Gunnarsen KS, Aase A, Michaelsen TE,

506 Sandlie I, Andersen JT. 2015. Fc Engineering of Human IgG1 for Altered Binding to the

507 Neonatal Fc Receptor Affects Fc Effector Functions. J Immunol 194(11): 5497-508.

508 Gupta R, Jung E, Brunak S. 2004. Prediction of N-glycosylation sites in human proteins.

509 http://www.cbs.dtu.dk/services/NetNGlyc/

510 Guzman MG and Vazquez S. 2010. The complexity of antibody-dependent enhancement of

511 dengue virus infection. Viruses. 2(12): 2649-62.

512 Halstead SB and O'Rourke EJ.1977. Antibody-enhanced dengue virus infection in primate

513 leukocytes. Nature 265:739-741.

514 Hayes JM, Cosgrave EF, Struwe WB, Wormald M, Davey GP, Jefferis R, Rudd PM. 2014.

515 Glycosylation and Fc receptors. Curr Top Microbiol Immunol. 382:165-99.

516 Hayes JM, Wormald MR, Rudd PM, Davey GP. 2016. Fc gamma receptors: glycobiology and

517 therapeutic prospects. Journal of Inflammatory Research. 9: 209-219. 
518 Higel F, Seidl A, Sörgel F, Friess W. 2016. N-glycosylation heterogeneity and the influence on

519 structure, function and pharmacokinetics of monoclonal antibodies and Fc fusion proteins. Eur J

520 Pharm Biopharm 100: 94-100.

521 Hossler P, Khattak SF, Li ZJ. 2009. Optimal and consistent protein glycosylation in mammalian 522 cell culture. Glycobiology; 19(9):936-49.

523 Hristodorov D, Fischer R, Linden L. With or without sugar? (A)glycosylation of therapeutic 524 antibodies. 2013. Mol Biotechnol 54(3): 1056-68.

525 Jefferis R, Lund J, Pound JD. 1998. IgG-Fc-mediated effector functions: molecular definition of 526 interaction sites for effector ligands and the role of glycosylation. Immunol Rev 163:59-76.

527 Konishi E, Tabuchi Y, Yamanaka A. 2010. A simple assay system for infection-enhancing and

528 neutralizing antibodies to dengue type 2 virus using layers of semi-adherent K562 cells. Journal 529 of Virological Methods 163: 360-367.

530 Kellner C, Derer S, Valerius T, Peipp M. 2014. Boosting ADCC and CDC activity by Fc 531 engineering and evaluation of antibody effector functions. Methods 65(1):105-13.

532 Kuhn RJ, Zhang W, Rossmann MG, Pletnev SV, Corver J, Lenches E, Jones CT,

533 Liming L. 2015. Antibody Glycosylation and Its Impact on the Pharmacokinetics

534 and Pharmacodynamics of Monoclonal Antibodies and Fc-Fusion Proteins. J Pharm Sci.

535 104(6):1866-1884.

536 Mukhopadhyay S, Chipman PR, Strauss EG, Baker TS, Strauss JH. 2002. Structure of dengue

537 virus: implications for flavivirus organization, maturation, and fusion. Cell 108:717-725.

538 Marasco WA, Sui J. 2007. The growth and potential of human antiviral monoclonal antibody

539 therapeutics, Nat. Biotechnology 25: 1421-1434. 
540 Murphy BR and Whitehead SS. 2011. Immune response to dengue virus and prospects for a

541 vaccine. Annu Rev Immunol 29: 587-619.

542 Natasha Evelyn AM, Mikkel BQ, Annelies WS. 2013. Epidemiology of dengue: past, present

543 and future prospects. Clinical Epidemiology 5:299-309.

544 Nesspor TC, Raju TS, Chin CN, Vafa O, Brezski RJ. 2012. Avidity confers Fc $\gamma$ R binding and

545 immune effector function to aglycosylated immunoglobulin G1. J Mol Recognit 25(3):147-54.

546 Nimmerjahn F and Ravetch JV. 2008. Fc gamma receptors as regulators of immune responses.

547 Nat Rev Immunol 8(1):34-47.

548 Omokoko MD, Pambudi S, Phanthanawiboon S, Masrinoul P, Setthapramote C, Sasaki T,

549 Kuhara M, Ramasoota P, Yamashita A, Hirai I, Ikuta K, Kurosu T. 2014. A highly conserved

550 region between amino acids 221 and 266 of dengue virus non-structural protein 1 is a major

551 epitope region in infected patients, Am. J. Trop. Med. Hyg 91:146-155.

552 Low JG, Ooi EE, Vasudevan SG. 2017. Current Status of Dengue Therapeutics Research and

553 Development. J Infect Dis :215(suppl_2):S96-S102.

554 Pitaksajjakul P, Benjathummarak S, Pipattanaboon C, Wongwit W, Okabayashi T, Kuhara M,

555 Misaki R, Fujiyama K, Ramasoota P. 2014. Antibody germline characterization of cross-

556 neutralizing human IgGs against 4 serotypes of dengue virus, Biochemical Biophysical Research

557 Communication 446: 475-480.

558 Ramadhany R, Hirai I, Sasaki T, Ono K, Ramasoota P, Ikuta K, Kurosu T. 2015. Antibody with

559 an engineered Fc region as a therapeutic agent against dengue virus infection. Antiviral Research

560 124: $61-68$.

561 Rowley MJ, O'Connor K, Wijeyewickrema L. 2004. Phage display for epitope determination: a

562 paradigm for identifying receptor-ligand interactions. Biotechnol Annu Rev 10:151-88. 
563 Sasaki T, Setthapramote C, Kurosu T, Nishimura M, Asai A, Omokoko MD, Pipattanaboon C,

564 Pitaksajjakul P, Limkittikul K, Subchareon A, Chaichana P, Okabayashi T, Hirai I,

565 Leaungwutiwong P, Misaki R, Fujiyama K, Ono K, Okuno Y, Ramasoota P, Ikuta K. 2013.

566 Dengue virus neutralization and antibody-dependent enhancement activities of human

567 monoclonal antibodies derived from dengue patients at acute phase of secondary infection,

568 Antiviral Research 98: 423-431.

569 Sazinsky SL, Ott RG, Silver NW, Tidor B, Ravetch JV, Wittrup KD. 2008. Aglycosylated

570 immunoglobulin G1 variants productively engage activating Fc receptors. Proc Natl Acad Sci U

$571 S$ A 105(51):20167-72.

572 Schieffelin JS, Costin JM, Nicholson CO, Orgeron NM, Fontaine KA, Isern S, Michael SF,

573 Robinson JE. 2010. Neutralizing and non-neutralizing monoclonal antibodies against dengue

574 virus E protein derived from a naturally infected patients. Virol J 7:28.

575 Schmidt AC. 2010. Response to dengue fever - the good, the bad, and the ugly? New England

576 Journal of Medicine 363: 484-487.

577 Setthapramote C, Sasaki T, Puiprom O, Limkittikul K, Pitaksajjakul P, Pipattanaboon C,

578 Sasayama M, Leungwutiwong P, Phumratanaprapin W, Chamnachanan S, Kusolsuk T,

579 Jittmittraphap A, Asai A, Arias JF, Hirai I, Kuhara M, Okuno Y, Kurosu T, Ramasoota P, Ikuta

580 K. 2012. Human monoclonal antibodies to neutralize all dengue virus serotypes using

581 lymphocytes from patients at acute phase of the secondary infection, Biochemical Biophysical

582 Research Communication 423: 867-872.

583 Shrestha B, Brien JD, Sukupolvi-Petty S, Austin SK, Edeling MA, Kim T, O'Brien KM, Nelson

584 CA, Johnson S, Fremont DH, Diamond MS. 2010. The development of therapeutic antibodies 
585 that neutralize homologous and heterologous genotypes of dengue virus type 1. PLoS Pathog 6:

$586 \mathrm{e} 1000823$.

587 Skottrup PD, Sørensen G, Ksiazek M, Potempa J, Riise E. 2012. A phage display selected 7-mer

588 peptide inhibitor of the Tannerella forsythia metalloprotease-like enzyme Karilysin can be

589 truncated to Ser-Trp-Phe-Pro. PLoS One 7(10): e48537.

590 Subedi GP, Barb AW. 2015. The structural role of antibody N-glycosylation in receptor

591 interactions. Structure 23: 1573-1583.

592 Sukupolvi-Petty S, Austin SK, Engle M, Brien JD, Dowd KA, Williams KL, Johnson S, Rico-

593 Hesse R, Harris E, Pierson TC, Fremont DH, Diamond MS. 2010. Structure and function

594 analysis of therapeutic monoclonal antibodies against dengue virus type 2. J Virol 84(18): 9227-

5959239.

596 Sun EC, Ma JN, Liu NH, Yang T, Zhao J, Geng HW, Wang LF, Qin YL, Bu ZG, Yang YH,

597 Lunt RA, Wang LF, Wu DL. 2011. Identification of two linear B-cell epitopes from West Nile

598 virus NS1 by screening a phage-displayed random peptide library. BMC Microbiol. 11:160.

599 Tao MH, Morrison SL. 1989. Studies of aglycosylated chimeric mouse-human IgG. Role of

600 carbohydrate in the structure and effector functions mediated by the human IgG constant region,

601 Journal of Immunology 143: 1595-1601.

602 Tewawong N, Pitaksajjkul P, Dekumyoy P, Ekpo P, Ramasoota P. 2012. Mimotope

603 identification using phage displayed random peptide libraries against monoclonal antibodies

604 specific to house dust mite. Southeast Asian J Trop Med Public Health 43(3): 614-623.

605 Williams KL, Sukupolvi-Petty S, Beltramello M, Johnson S, Sallusto F, Lanzavecchia A. 2013.

606 Therapeutic efficacy of antibodies lacking Fc $\gamma$ receptor binding against lethal dengue virus 
607 infection is due to neutralizing potency and blocking of enhancing antibodies. PLoS Pathog 9(2):

608 e1003157.

609 Xue M, Shi X, Zhang J, Zhao Y, Cui H, Hu S, Gao H, Cui X, Wang YF. 2012. Identification of a

610 conserved B-cell epitope on reticuloendotheliosis virus envelope protein by screening a phage-

611 displayed random peptide library. PLoS One 7(11):e49842.

612 Zhang F, Yu M, Zhang N, Wang LF. 2006. Characterization of epitopes form neutralizing

613 monoclonal antibodies to classical swine fever virus E2 and Erns using phage-displayed random

614 peptide library. Arch Virol 151: 37-54.

615 Zhang RY, Shen WD. 2012. Monoclonal antibody expression in mammalian cells. Methods Mol

616 Biol; 907: 341-58.

617 Zhao J, Sun EC, Liu NH, Yang T, Xu QY, Qin YL, Yang YH, Wu DL.2012. Phage display

618 identifies an eastern equine encephalitis virus glycoprotein E2-specific B cell epitope. Vet

619 Immunol Immunopathol 148:364-368.

620

621 Figure Legend

622 Figure 1. Immunofluorescence assay of B3B9 and N297Q-B3B9 rIgG against four DENV

623 serotypes. Vero cells were infected with DENV1, 2, 3, or 4 at MOI 0.1 . The ability of the

624 HuMAbs B3B9 (A-D) and N297Q-B3B9 rIgG (F-I) in the culture supernatants of HEK293T

625 cells transiently expressing these antibodies to bind to different serotypes of DENV was assessed

626 by performing IFAs. (E,J). Negative control of mock infected cells. Representative images are

627 shown.

628 Figure 2. Neutralizing activity of N297Q-B3B9 and B3B9 rIgG antibody against four DENV

629 serotypes. NT levels of N297Q-B3B9 rIgG and B3B9 rIgG of DENV1-4 (A-D) in Vero cells 
630 were assessed by foci reduction neutralization tests. The foci of infected cells were counted and 631 compared with the no antibody control, and the results were calculated as the percent reduction

632 in focus forming units. The number of foci was calculated as the average of triplicate

633 experiments. (The error bars show standard deviation of the experiments). (E) NT50

634 concentration (concentration that used for reduce half of infected cells when compared with 635 control) of N297Q-B3B9 and B3B9 rIgG antibody against DENV serotypes.

636 Figure 3. ADE assays in K562and THP-1 cells. (A-D) Enhancement activity against the four 637 DENV serotypes in Fc $\gamma$ RII-bearing K562 cells. The number of infected cells $\left(\log _{10}\right)$ from each 638 antibody concentration compared with that of the control without antibody is shown. The 639 numbers of infected cells were derived from the average of the counted infected cells from three 640 frames at 20x magnification multiplied by a surface area amplification factor to obtain the total 641 number of cells in each well. Dotted lines indicate cut-off values for differentiating neutralizing 642 and enhancing activity from the average plus three times the SD of the percentages of infected 643 cells obtained with the four negative controls. (The error bars show standard deviation of the 644 repeated experiments). (E-H) ADE assay on THP-1 cells. The antibody concentration was 645 serially diluted ten-fold and are represented on the X-axis. The fold enhancement in the virus 646 copy number of the sample with each antibody was compared with that of the no antibody 647 control and is represented on the $\mathrm{Y}$-axis. The plotted values were obtained from the average of 648 duplicates from two repeated experiments.

649 Figure 4. Epitope mapping by phage display of random peptide libraries. (A) Affinity selection 650 of phage-display. Ph.D.-12 and Ph.D.-C7C Phage Display Peptide Libraries were used in 651 biopanning step. The constant units of phage $\left(5 \times 10^{10} \mathrm{PFU}\right)$ was used for three rounds of 652 biopanning. Increasing of percent yields of output phages represents the specific enrichment. (B) 
653 Alignment of phage-displayed peptide sequences selected by HuMAbs. Phage clones were 654 shown to display a consensus sequences LXXXG (show in the box) (C) Comparison of the 655 amino acid sequences of E proteins DENV1-4. In the box, DENV1-4 shared the same amino 656 acids at positions $107(\mathrm{~L}), 108(\mathrm{~F}), 109(\mathrm{G}), 110(\mathrm{~K})$, and $111(\mathrm{G})$. (D) Phage inhibition ELISA 657 of 8 phage clones which matched to the motif of 107LXXXG111. Phage lysate of selected 658 clones bound with HuMAb in solution phase and the free phage clones were detected by ELISA. 659 The absorbance values were measured at $450 \mathrm{~nm}$ using an ELISA reader (TECAN). Absorbance 660 values of each concentration (A) were divided by absorbance values of no antibody (control) 661 (A0), resulting in normalized values (A/A0). Anti-influenza antibody was used as negative 662 control.

663 Figure 5. The NT and ADE activity against DENV2 of N297Q-B3B9 rIgG derived from a 664 stable and transient CHO-K1 cell line. A line of CHO-K1 cells stably expressing N297Q-B3B9 665 rIgG was established. (A) The NT of N297Q-B3B9 rIgG against DENV2. The X-axis represents 666 the concentration of antibodies, and the Y-axis represents the percent reduction in focus-forming 667 units compared with the foci number of the control sample that lacked antibody. The number of 668 foci was calculated as the average of triplicate experiments. (B) An ADE assay of N297Q-B3B9 669 rIgG against DENV2 was performed in K562 cells. The infected cells were counted at each 670 antibody concentration and compared with the control (DENV2-infected cells without antibody).

671 Dotted lines indicate cut-off values for differentiating neutralizing and enhancing activity from 672 the average plus three times the SD of the percentages of infected cells obtained with the four 673 negative controls. (The error bars show standard deviation of the repeated experiments). 674 
675 Table 1. The consensus peptide sequences of eight selected phage clones. These clones matched 676 to the motif 107LXXXG111 of DENV genome.

677

678 Supplement figure 1. PCR isotyping of N297Q-1B3B9 rIgG. First lane was 100 bps DNA

679 ladder. Second lane was the sample that amplified from the same forward primer of IgG1 and

$680 \mathrm{IgG} 3$; third lane was the sample amplified by forward primer of IgG2 and last lane was the

681 sample amplified by forward primer of IgG4. All of isotypes used the same reverse primer. The 682 expected sizes of the PCR products were 211, 207, 346, and $210 \mathrm{bp}$ for IgG1, IgG2, IgG3, and 683 IgG4, respectively.

684

685 Supplement table 1. Primers used for IgG isotype identification 686

687

688 


\section{Figure 1}

Immunofluorescence assay of B3B9 and N297Q-B3B9 rlgG against four DENV serotypes.

Vero cells were infected with DENV1, 2, 3, or 4 at MOI 0.1 . The ability of the HuMAbs B3B9 (A-D) and N297Q-B3B9 rlgG (F-I) in the culture supernatants of HEK293T cells transiently expressing these antibodies to bind to different serotypes of DENV was assessed by performing IFAs. $(E, J)$. Negative control of mock infected cells. Representative images are shown. 
B3B9 rIgG

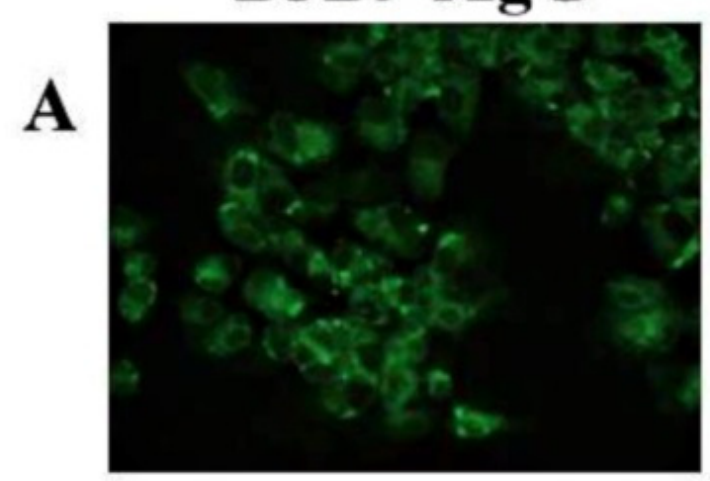

B

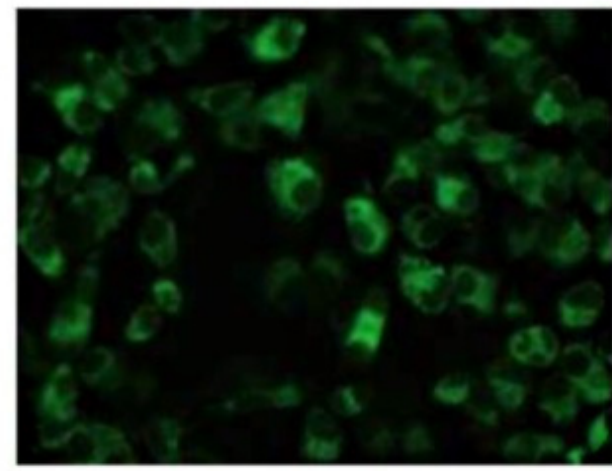

C

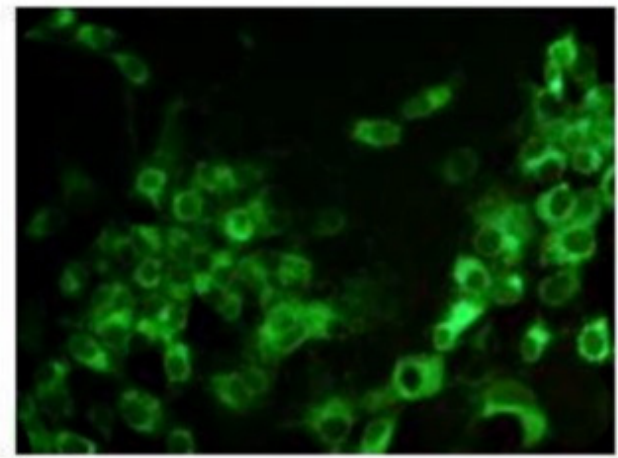

D

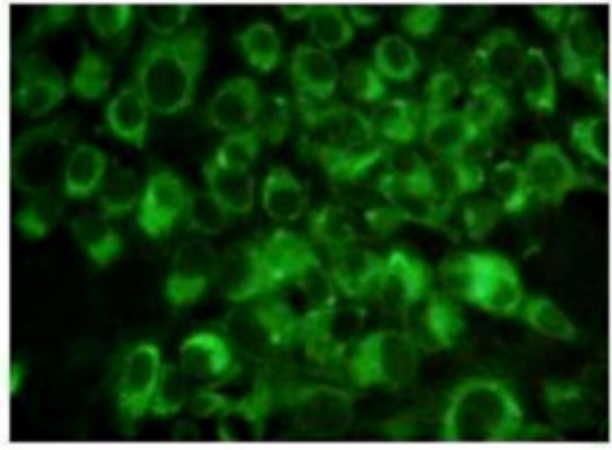

E
N297Q-B3B9 rIgG

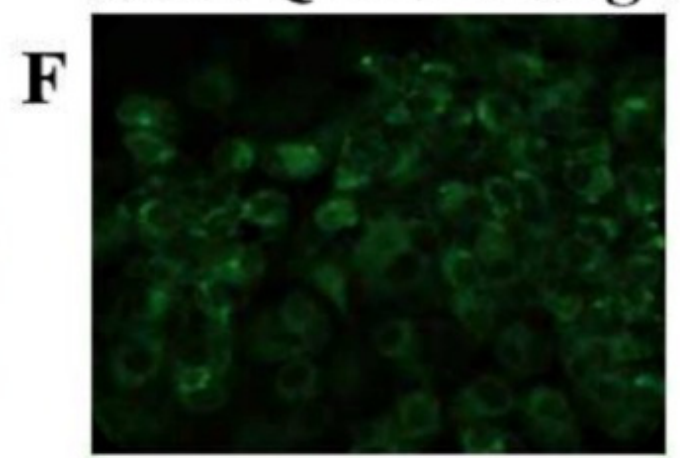

DENV1

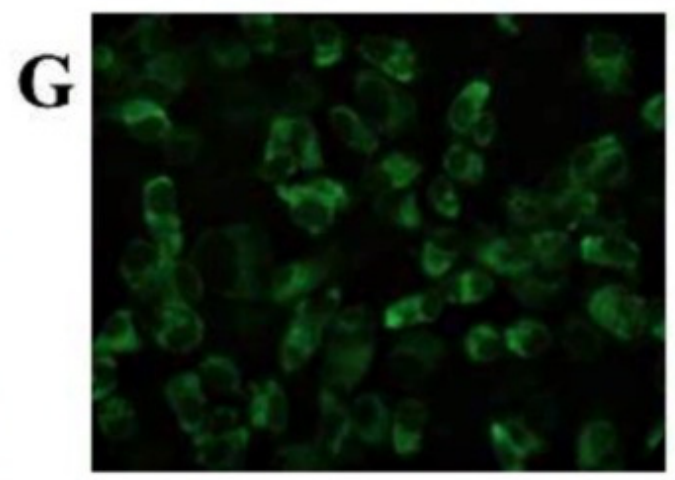

DENV2

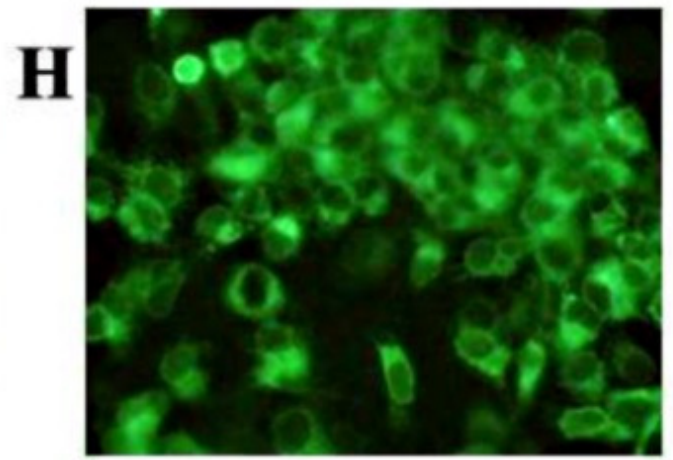

DENV3

I

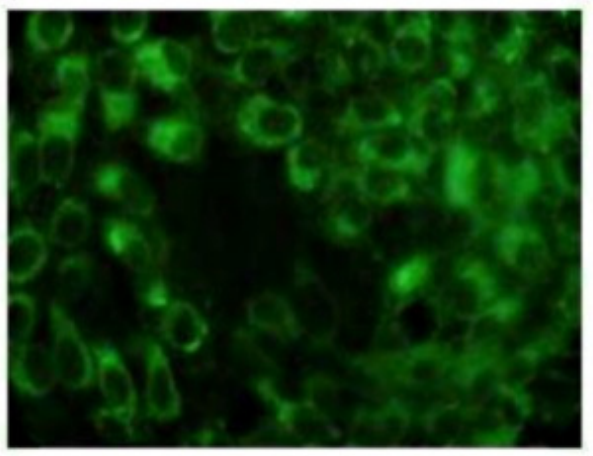

DENV4

Control 


\section{Figure 2}

Neutralizing activity of N297Q-B3B9 and B3B9 rlgG antibody against four DENV serotypes.

NT levels of N297Q-B3B9 rlgG and B3B9 rlgG of DENV1-4 (A-D) in Vero cells were assessed by foci reduction neutralization tests. The foci of infected cells were counted and compared with the no antibody control, and the results were calculated as the percent reduction in focus forming units. The number of foci was calculated as the average of triplicate experiments. (The error bars show standard deviation of the experiments). (E) NT50 concentration (concentration that used for reduce half of infected cells when compared with control) of N297Q-B3B9 and B3B9 rlgG antibody against DENV serotypes. 
$\mathbf{A}$

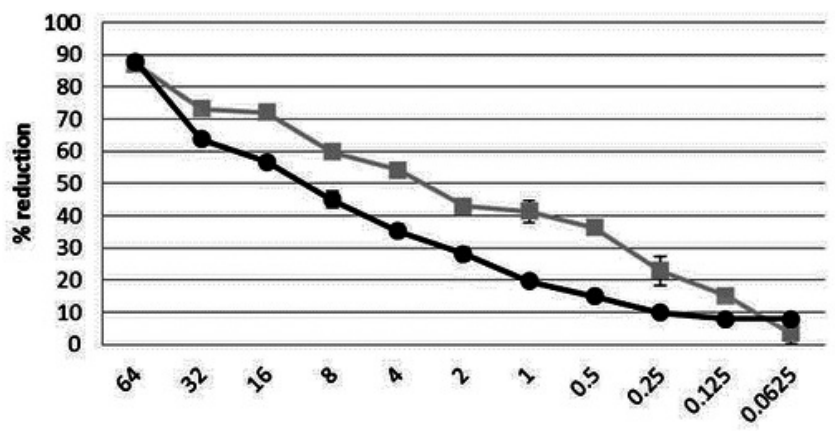

C

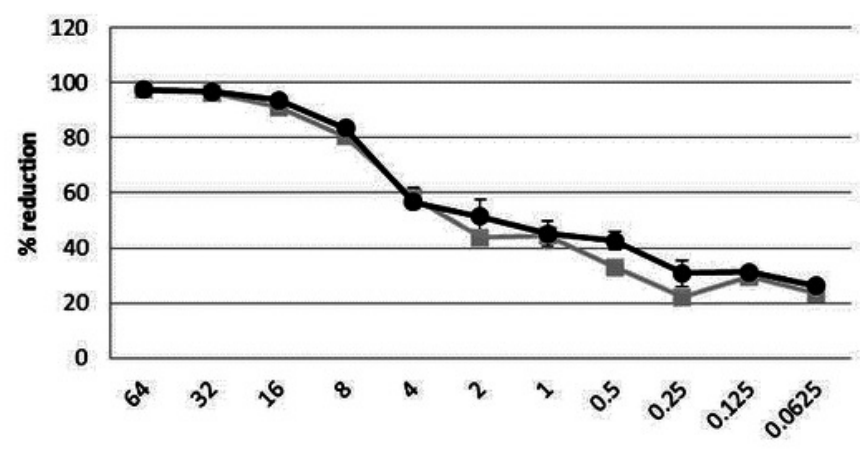

B DENV2

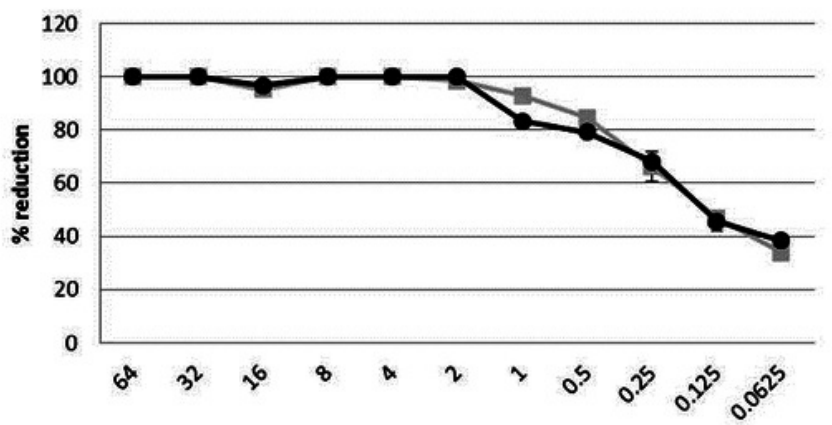

D

\section{DENV4}

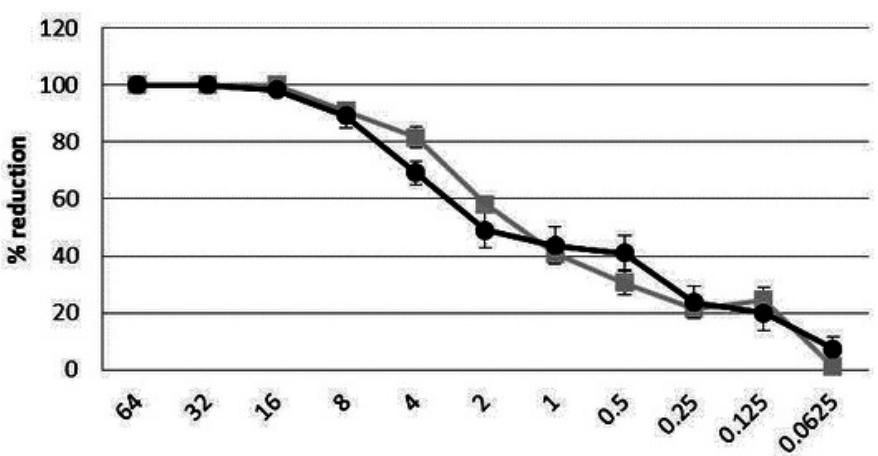

Antibody concentration $(\mu \mathrm{g} / \mathrm{ml})$

\begin{tabular}{|c|c|c|c|c|}
\hline \multirow{2}{*}{ Antibody } & \multicolumn{4}{|c|}{ Neutralizing activity (NT50) ( $\mathrm{\mu g} / \mathrm{ml})$} \\
\cline { 2 - 5 } & DENV1 & DENV2 & DENV3 & DENV4 \\
\hline rigG & 3 & 0.125 & 2 & 2 \\
\hline N297Q rigG & 12 & 0.125 & 2 & 2 \\
\hline
\end{tabular}




\section{Figure 3}

ADE assays in K562and THP-1 cells.

(A-D) Enhancement activity against the four DENV serotypes in FcyRIl-bearing K562 cells.

The number of infected cells $\left(\log _{10}\right)$ from each antibody concentration compared with that of the control without antibody is shown. The numbers of infected cells were derived from the average of the counted infected cells from three frames at 20x magnification multiplied by a surface area amplification factor to obtain the total number of cells in each well. Dotted lines indicate cut-off values for differentiating neutralizing and enhancing activity from the average plus three times the SD of the percentages of infected cells obtained with the four negative controls. (The error bars show standard deviation of the repeated experiments). (EH) ADE assay on THP-1 cells. The antibody concentration was serially diluted ten-fold and are represented on the X-axis. The fold enhancement in the virus copy number of the sample with each antibody was compared with that of the no antibody control and is represented on the Y-axis. The plotted values were obtained from the average of duplicates from two repeated experiments.
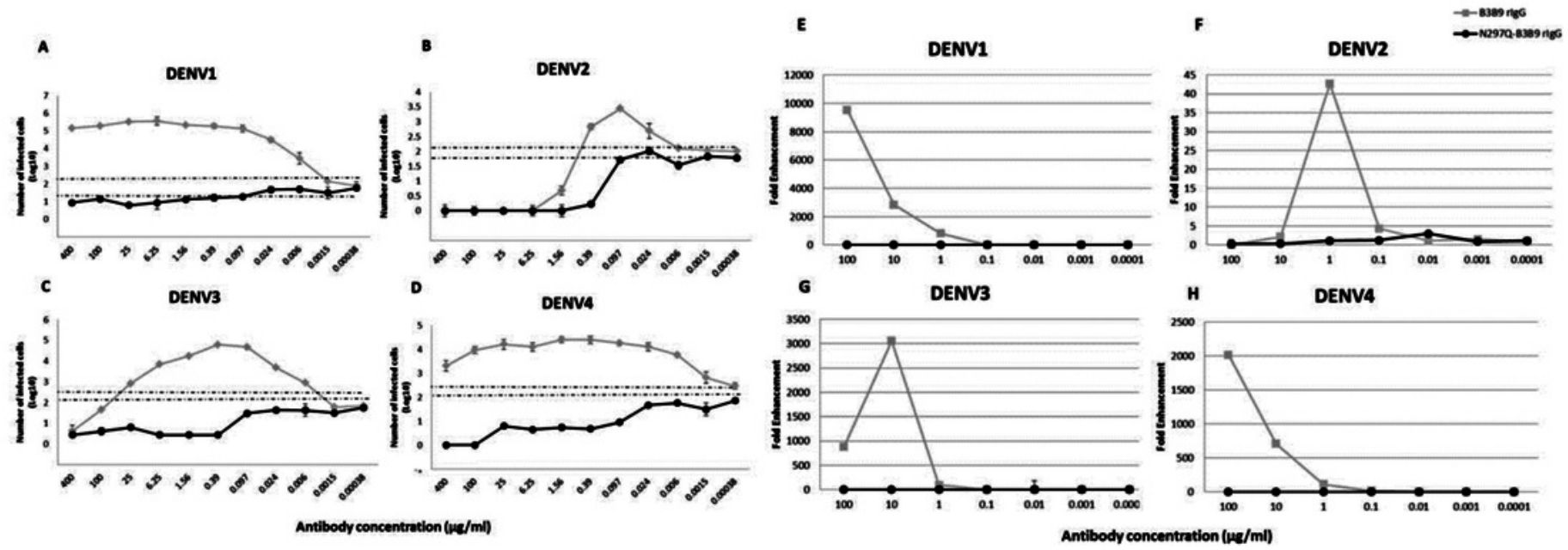


\section{Figure 4}

Epitope mapping by phage display of random peptide libraries.

(A) Affinity selection of phage-display. Ph.D.-12 and Ph.D.-C7C Phage Display Peptide Libraries were used in biopanning step. The constant units of phage $\left(5 \times 10^{10} \mathrm{PFU}\right)$ was used for three rounds of biopanning. Increasing of percent yields of output phages represents the specific enrichment. (B) Alignment of phage-displayed peptide sequences selected by HuMAbs. Phage clones were shown to display a consensus sequences LXXXG (show in the box) (C) Comparison of the amino acid sequences of E proteins DENV1-4. In the box, DENV1-4 shared the same amino acids at positions 107 (L), $108(\mathrm{~F}), 109(\mathrm{G}), 110(\mathrm{~K})$, and 111 (G). (D) Phage inhibition ELISA of 8 phage clones which matched to the motif of 107LXXXG111. Phage lysate of selected clones bound with HuMAb in solution phase and the free phage clones were detected by ELISA. The absorbance values were measured at $450 \mathrm{~nm}$ using an ELISA reader (TECAN). Absorbance values of each concentration (A) were divided by absorbance values of no antibody (control) $(A 0)$, resulting in normalized values (A/A0). Antiinfluenza antibody was used as negative control. 


A
\begin{tabular}{|l|c|c|l|}
\hline For Ph.D. C7C & Input phage (PFU) & Output phage (PFU) & Vield (\%) \\
\hline Round 1 & $5 \times 10^{10}$ & $6.9 \times 10^{5}$ & 0.0014 \\
\hline Round 2 & $5 \times 10^{10}$ & $1.01 \times 10^{8}$ & 0.202 \\
\hline Round 3 & $5 \times 10^{10}$ & $9.8 \times 10^{8}$ & 1.96 \\
\hline For Ph.D. 12 & & & \\
\hline Round 1 & $5 \times 10^{10}$ & $6.9 \times 10^{5}$ & 0.0014 \\
\hline Round 2 & $5 \times 10^{10}$ & $2.4 \times 10^{8}$ & 0.48 \\
\hline Round 3 & $5 \times 10^{10}$ & $7.7 \times 10^{8}$ & 1.54 \\
\hline
\end{tabular}

C

B

\begin{tabular}{|c|c|c|c|}
\hline C7C_2-2 & H G F Y D & L E C G G & \\
\hline C7C_2-6 & H G F Y D & L E C G G & \\
\hline C7C_3-1 & H G F Y D & L $E$ C $C$ G G & \\
\hline C7C_3-2 & H G F Y D & L E C G G & \\
\hline C7C_3-7 & H G F & $L E C G G$ & \\
\hline PhD12_2-1 & $s \mathrm{~s} w$ & L Q S Y G & L T T H \\
\hline PhD12_2-3 & $s \mathrm{~s} w$ & L Q S Y G & L T T H \\
\hline PhD12_2-4 & $s \mathrm{~s} w$ & L Q S $\quad$ Y G & L T T H \\
\hline PhD12_3-4 & $s \mathrm{~s}$ w & L Q S Y G & L T T H \\
\hline PhD12_3-10 & $s \mathrm{~s}$ w & L $Q$ Q $S$ Y & L T T H \\
\hline PhD12_2-2 & S N F & $\mathrm{L} \quad \mathrm{S} A \mathrm{~A} \quad \mathrm{Y}$ G & W N V G \\
\hline PhD12_2-7 & $S$ P G W & L T S S Y G & w T T \\
\hline PhD12_3-1 & N S F & L G A Y G & W L E A \\
\hline PhD12_3-6 & N S F & $\mathrm{L}, \mathrm{G} A \mathrm{Y}$ G & W L E A \\
\hline PhD12_3-7 & $S Y N P F$ & $\mathrm{~L} A \mathrm{~S} \quad \mathrm{Y}$ G & w w \\
\hline PhD12_3-9 & H N R T & L D A $A$ & L D \\
\hline PhD12_3-12 & - & L $\quad E \quad R \quad$ Y & L A S V Q \\
\hline PhD12_2-5 & $\mathrm{v} \mathrm{N} \mathrm{w} \mathrm{w}$ & Q Q E L L & L K \\
\hline PhD12_2-9 & W S G F & D L P,$T$ & T R \\
\hline PhD12_2-11 & V S S S R & V F H S & w w \\
\hline PhD12_3-5 & W S G F Y & D L P,$T$ & T R \\
\hline PhD12_3-8 & Y V R T & F L S A & E R \\
\hline
\end{tabular}

D

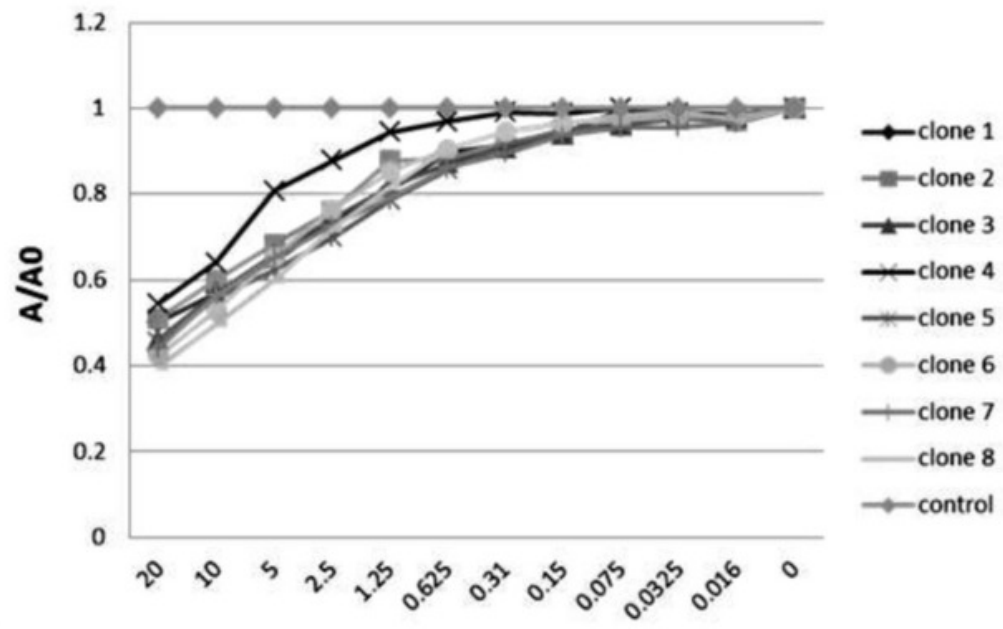

Antibody concentration $(\mu \mathrm{g} / \mathrm{ml})$ 


\section{Figure 5}

The NT and ADE activity against DENV2 of N297Q-B3B9 rlgG derived from a stable and transient $\mathrm{CHO}-\mathrm{K} 1$ cell line.

A line of CHO-K1 cells stably expressing N297Q-B3B9 rlgG was established. (A) The NT of N297Q-B3B9 rlgG against DENV2. The X-axis represents the concentration of antibodies, and the $Y$-axis represents the percent reduction in focus-forming units compared with the foci number of the control sample that lacked antibody. The number of foci was calculated as the average of triplicate experiments. (B) An ADE assay of N297Q-B3B9 rlgG against DENV2 was performed in K562 cells. The infected cells were counted at each antibody concentration and compared with the control (DENV2-infected cells without antibody). Dotted lines indicate cutoff values for differentiating neutralizing and enhancing activity from the average plus three times the SD of the percentages of infected cells obtained with the four negative controls. (The error bars show standard deviation of the repeated experiments). 
A

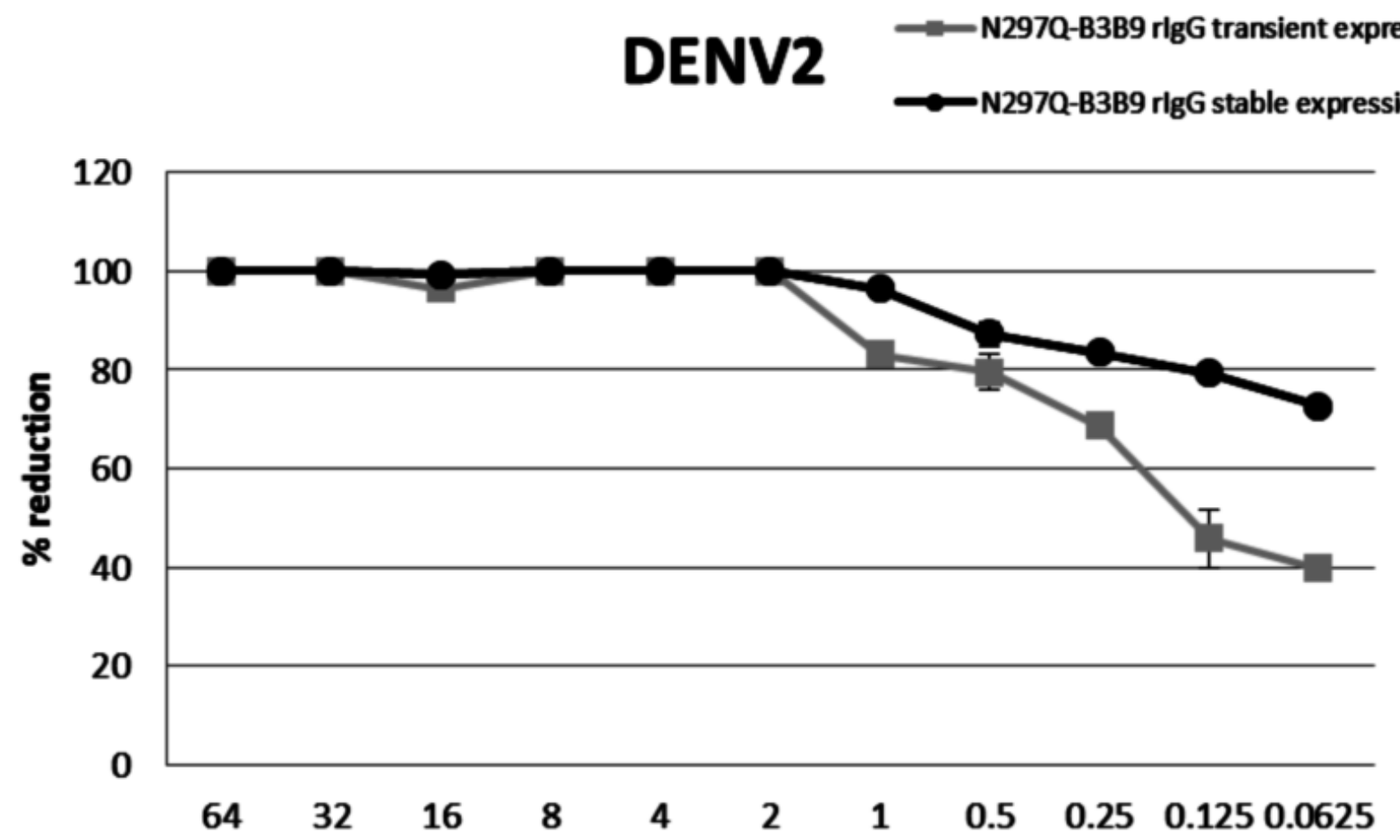

B

DENV2

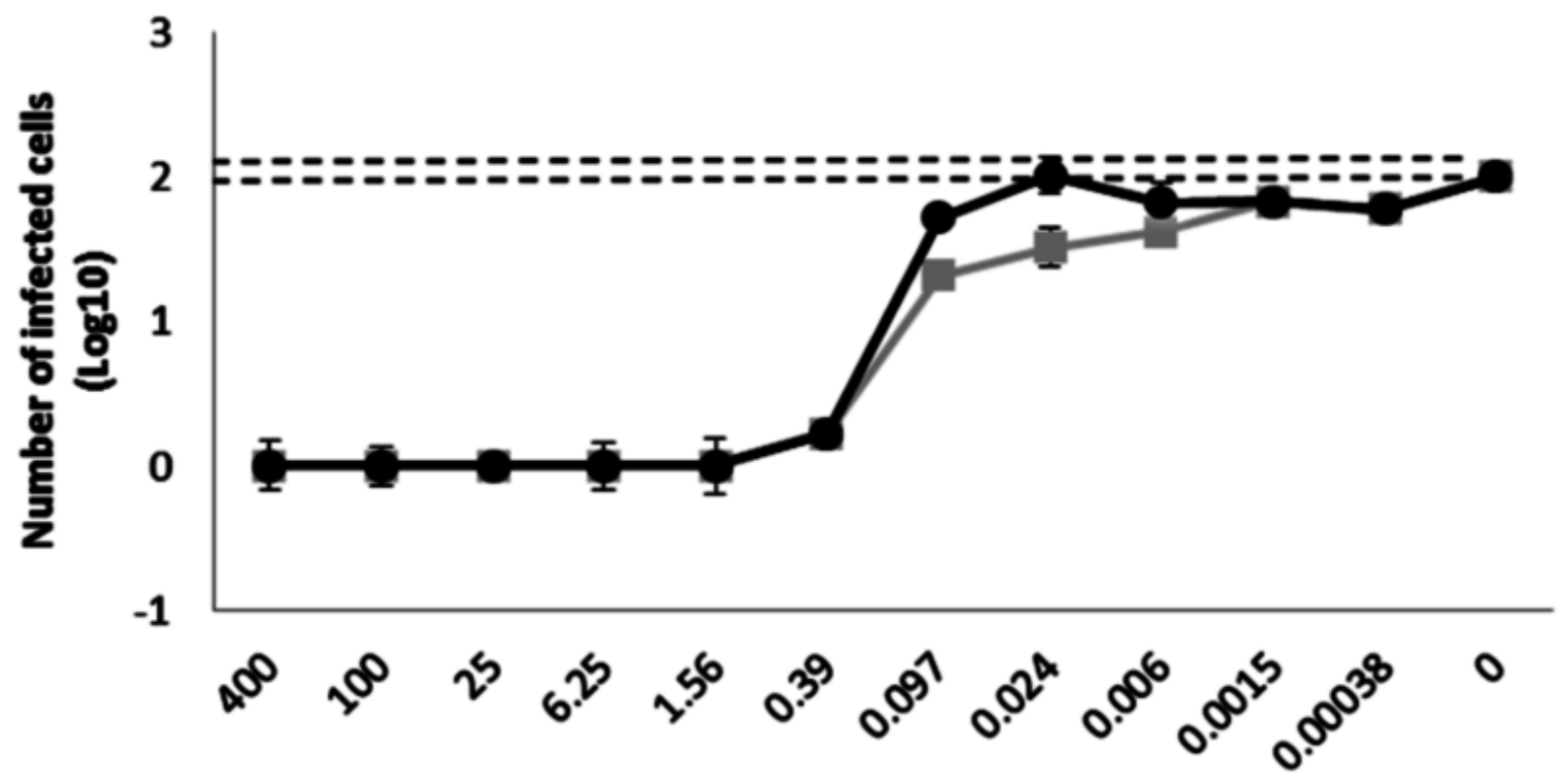

Antibody concentration ( $\mu \mathrm{g} / \mathrm{ml})$ 


\section{Table $\mathbf{1}$ (on next page)}

The consensus peptide sequences of eight selected phage clones.

These clones matched to the motif 107LXXXG111 of DENV genome. 


\begin{tabular}{|c|c|}
\hline Clone number & Consensus Sequences \\
\hline 1 & LECGG \\
\hline 2 & LQSYG \\
\hline 3 & LSAYG \\
\hline 4 & LTSYG \\
\hline 5 & LGAYG \\
\hline 6 & LASYG \\
\hline 7 & LDAYG \\
\hline 8 & LERYG \\
\hline
\end{tabular}

